Article

\title{
Evaluation of Chicken Feather and Styrene-Butadiene/Chicken Feather Composites as Modifier for Asphalts Binder
}

\author{
Leslie Mariella Colunga-Sánchez, Beatriz Adriana Salazar-Cruz, José Luis Rivera-Armenta *(D), \\ Ana Beatriz Morales-Cepeda ${ }^{\circledR}$, Claudia Esmeralda Ramos-Gálvan and \\ María Yolanda Chávez-Cinco \\ Petrochemical Research Center, Tecnológico Nacional de México/Instituto Tecnológico de Ciudad Madero, \\ Altamira, Tamaulipas 89600, Mexico; lelie120@hotmail.com (L.M.C.-S.); \\ beatrizadriana1973@hotmail.es (B.A.S.-C.); acepeda71@yahoo.com (A.B.M.-C.); \\ cesmeralda@hotmail.com (C.E.R.-G.); yolcin5@yahoo.com.mx (M.Y.C.-C.) \\ * Correspondence: jlriveraarmenta@itcm.edu.mx; Tel.: +52-833-283-2973
}

Received: 11 October 2019; Accepted: 27 November 2019; Published: 29 November 2019

\begin{abstract}
In the present work, the evaluation of chicken feather particles (CFP) and styrene-butadiene/ chicken feather (SBS-CF) composites as modifiers for asphalt binder is presented. It is well known that elastomers are the best asphalt modifiers, because their thermoplastic behavior assists asphalts in improving the range of their mechanical properties at both low and high temperatures. Nowadays, the use of natural products and byproducts as fillers for polymer matrices has been a matter of research, and the field of asphalt modification is not the exception. Chicken feather particles (CFP) is a waste material whose main component is keratin, which offers remarkable properties. In the present work, CFP was used as a filler of a styrene-butadiene rubber matrix (SBS) with radial structure, to obtain a composite intended as an asphalt modifier. Besides, raw CFP was also tested as an asphalt modifier. Physical, thermal and rheological properties of the modified asphalts were evaluated in order to determine their degree of modification with respect to the original asphalt. The results show that the addition of raw CFP improves some physical properties as penetration and decreases the phase separation; furthermore, the asphalt modified with CFP displayed similar rheological properties to those shown by the asphalt modified with SBS, while some other properties resulted in being even better, like the phase separation, with the advantage that the CFP comes from a natural waste product.
\end{abstract}

Keywords: chicken feathers; SBS elastomers; composite; rheology

\section{Introduction}

The increasing vehicular flow, as well as dramatic climate change, are some of the main causes of road asphalt distress; therefore, it is necessary to improve its performance. The growing need of improving the properties of the currently available commercial asphalts has attracted the interest of many research groups in order to study different asphalt modifiers that are able to enhance its properties while minimizing the damage caused by rutting, fractures, raveling, cracking, etc. Moreover, the high production costs, which are directly related to the international prices of crude oil, as well as the high level of pollution involved in the processing of asphalt, are also restrictions demanding new materials that meet not only quality but also environmentally friendly criteria, as well as low cost. These motivations are encouraging researchers to employ waste materials as modifiers of asphalt blends with the purpose of using sustainable resources in asphalt modification technology. 
Asphalt binder is an asphalt cement that can be classified according to the Standard Specification for Performance Graded Asphalt Binder (ASSHTO). This classification is valid for either modified or unmodified asphalts.

In recent years, bio-asphalts have become a popular trend among asphalt modification techniques because their preparation implies using renewable sources of energy, as well as natural materials like bio-oils or biomass [1]; however, their performance at high temperatures is deficient [2,3], mainly because the addition of oil reduces the viscosity of the asphalt and affects its stiffness. Some studies have reported that the addition of waste wood into bio-asphalts contributes to enhancing their low temperature performance [1], while in some other cases no significant effects on the rutting performance and dynamic modulus are reported [4]. Consequently, a combination of different oils and the incorporation of polymer modifiers, as SBS [5], may be required to improve the asphalt behavior. Nevertheless, the long-term performance of bio-asphalts still needs to be verified [1].

One of the most conventional and easy ways to produce modified asphalts is preparation by hot mixing, since it allows the addition of differently shaped and sized particles, which are responsible for the viscoelastic behavior of the final blend due to the physical interactions between the modifier particles and the asphalt components [6,7]. Previous works have reported the successful addition of oyster shells as filler substitutes [8]. Various waste materials, such as egg shell powder, have also been evaluated as sustainable modifiers, which has resulted in discovering promising modifiers for asphalt mixtures [9]. Other works have reported that vegetal and mineral fibers [1]; lignin [10]; agroindustrial wastes such sugarcane bagasse, corncobs and rice husk ash [11-13]; and epoxidized soybean oil [14], can be used to improve the rheological, physical and mechanical properties of asphalt binders when they are used at concentrations ranging from $1 \%$ to $20 \% \mathrm{w}$.

Some of the most remarkable agents for asphalt modification include polymer/nanoclay composites [15-17], recycled polymers like ground rubber, waste polyethylene, and recovered asphalt pavement $[18,19]$.

Composites can be defined as materials formed by a matrix that can be either ceramic, metallic or polymeric, and a filler, which is added to the matrix with the purpose of enhancing some of its properties. Styrene-butadiene-styrene copolymers (SBS) are thermoplastic polymers that find many fields of application because of the combination of their elastic and viscous natures. This feature is important in asphalt modification because it makes SBS able to transfer elastic properties to the asphalt, despite the fact that using this kind of modifier has both economic and technical limitations. Although polymeric modifiers have proven their efficiency, the compatibility between the asphalt and the polymer is still an important limitation that should be taken into account when new modifying agents are designed. The affinity between the binder and its modifier must be ensured in order to minimize the risk of phase separation due to the exposure to temperature and pressure changes, because it greatly affects the lifetime and general performance of the modified asphalt.

Studies introducing composites based on SBS rubbers and CFP as reinforcing filler have been recently reported $[20,21]$. The chicken feathers are fiber-structured proteins that can be leveraged along with a polymer to significantly improve the properties of other materials. For this reason, the effect of the addition of a composite based on SBS/CFP on the physicochemical properties of asphalts is studied in this research in order to evaluate its advantages regarding the conventional methods used in the asphalt modification field.

Aside from SBS/CFP composites, raw CFP was also proposed and evaluated as an asphalt modifier, and the effect of the sequence of addition of SBS and CFP on the properties of the asphalt mix at a fixed modifier concentration of $2 \%$ was analyzed in this study.

\section{Materials and Methods}

Clean chicken feathers (CF) were used in this work. First, they were washed with soap and water, then with an ethanol aqueous solution and finally with pure ethanol for sanitizing and deodorizing. Once clean, CFs were grinded by using a domestic blender and then sieved using a 20-mesh in order 
to obtain a homogenous particle size $(0.074 \mathrm{~mm})$ of chicken feather particles (CFP). The selected SBS (styrene-butadiene-styrene block copolymer) was radial structured with $31 \%$ of total styrene content and was provided by Dynasol Elastómeros, Altamira, Tamaulipas, México. The base asphalt binder used was a PG64-22 asphalt that was donated by Ergon Asfaltos México, Altamira, with the following SARA composition: saturates $8.38 \%$, aromatics $37.14 \%$, resins $36.33 \%$, and asphaltenes $28.15 \%$.

\subsection{Composite Preparation}

The polymer composites were prepared in a mixing chamber of $60 \mathrm{~cm}^{3}$ equipped with Roller blades. The amount of CFP was kept constant. The operating temperature was $80{ }^{\circ} \mathrm{C}$, and the tested rotation speeds were 50 and $70 \mathrm{rpm}$.

\subsection{Preparation of Modified Asphalt Mixtures}

Modified asphalt blends were prepared using a heating device with temperature control and an IKA-Eurostar Power control-visc 6000 stirrer. Both temperature $\left(180^{\circ} \mathrm{C}\right)$ and mixing speed were kept constant. Homogeneous dispersions of the modifiers into the asphalt were obtained. The amount of modifier was fixed at $2 \% \mathrm{wt}$ (weight percent) [11]. The following additional samples were prepared and identified: asphalt modified with pure SBS (M1), asphalt with pure CFP (M2) and asphalt-SBS-CFP; the latter sample was prepared considering two additional sequences of the additives into the asphalt: SBS followed by CFP represented sample M3, while CFP followed by SBS corresponded to sample M4. Finally, two SBS/CFP composites were prepared and tested as asphalt modifiers: The first composite was obtained at $50 \mathrm{rpm}$ and $80^{\circ} \mathrm{C}(\mathrm{M} 5)$ while the other was prepared at $70 \mathrm{rpm}$ and $80^{\circ} \mathrm{C}(\mathrm{M} 6)$. The nomenclature of these samples is displayed in Table 1.

Table 1. Codes employed for modified asphalts.

\begin{tabular}{ccccccc}
\hline Sample & $\begin{array}{c}\text { Asphalt } \\
\text { with SBS } \\
\text { (Control) }\end{array}$ & $\begin{array}{c}\text { Asphalt } \\
\text { with CF }\end{array}$ & $\begin{array}{c}\text { Asphalt } \\
\text { with } \\
\text { SBS + CF }\end{array}$ & $\begin{array}{c}\text { Asphalt } \\
\text { with } \\
\text { CF + SBS }\end{array}$ & $\begin{array}{c}\text { Asphalt with } \\
\text { SBS/CF } \\
\text { Composite 50 rpm }\end{array}$ & $\begin{array}{c}\text { Asphalt with } \\
\text { SBS/CF } \\
\text { Composite 70 rpm }\end{array}$ \\
\hline Code & M1 & M2 & M3 & M4 & M5 & M6 \\
\hline
\end{tabular}

\subsection{Physical Properties}

Dynamic viscosity was determined by means of a Brookfield DV-II+ Pro viscometer, using $10.5 \mathrm{~g}$ samples with an adapted geometry. Measurements were carried out at $135^{\circ} \mathrm{C}$. The ASTM D36/D36M-14e1 method was used to determine the asphalt softening point. The phase separation or storage stability test based on the ASTM D5892-00/M-MMP-4-05-022/02 methods allows us to identify the compatibility between the asphalt and its modifier and is considered as one of the main performance indicators of the efficiency of an asphalt modification technique. For carrying out this test, the modified asphalt mixture was poured into a collapsible tube, then aged at $163^{\circ} \mathrm{C}$ for $48 \mathrm{~h}$, and finally frozen at temperatures below $0{ }^{\circ} \mathrm{C}$. If the difference between the softening points of the top and the bottom sections of the tube is less than $3{ }^{\circ} \mathrm{C}$, the samples are considered to have good high-temperature storage stability. The ASTM D5/D5M-19 penetration test was carried out using a Koeler K95500 penetrometer in order to assess the consistency of the asphalt binder. Fluorescence microscopy was performed in a Carl Zeiss Axiotech equipment with a magnification of 20x; this technique is based on the optical phenomenon of fluorescence that allows to identify the dispersion of modifier particles within the asphalt, given that particles with better dispersion show no fluorescence. This property largely depends on the concentration of the modifier on the asphalt. The incident energy, usually in the range of UV light, is absorbed by the electronic structure of the specimen. Every test was carried out twice. 


\subsection{Thermal Analysis}

The Simultaneous Differential Scanning Calorimetry (DSC)/Thermogravimetric analysis (TGA) (SDT) measurements were used to evaluate the thermal stability of the asphalt blends by separation of component weight losses. For this purpose, a TA Instruments Q600 equipment was used to analyze $10 \pm 2 \mathrm{mg}$ samples, under nitrogen atmosphere $(100 \mathrm{~mL} / \mathrm{min})$, and at a heating rate of $10^{\circ} \mathrm{C} / \mathrm{min}$, using platinum pans.

\subsection{Rheological Analysis}

Dynamic rheological measurements of the asphalt blends were conducted in a Dynamic Shear Rheometer (DSR) of TA Instruments model Discovery HR-3 equipment. First, frequency and amplitude sweeps were run to recognize the linear viscoelastic region (LVR). Afterwards, a temperature sweep was performed under the oscillating mode fixing a deformation of $10 \%$ and $10 \mathrm{rad} / \mathrm{s}$ with temperatures ranging from 52 to $124^{\circ} \mathrm{C}$ at intervals of $6^{\circ} \mathrm{C}$. The behavior of the ratio of the complex modulus to the sinus of the phase angle $\left(\mathrm{G}^{*} / \sin \delta\right)$ as a function of the temperature was monitored at $10 \mathrm{rad} / \mathrm{s}$, since this value is associated with a $100 \mathrm{~km} / \mathrm{h}$ traffic speed [7].

\section{Results}

\subsection{Physical Properties}

Table 2 shows the physical properties of the asphalt binder. The softening point increased in all of the modified samples regarding the pristine asphalt; therefore, all these mixtures will be less susceptible to permanent deformations. The softening point behaved analogously to the viscosity since these two properties are closely related, this is consistent with the fact that asphalts with a high softening point are more viscous than those with a low softening point. Additionally, the processing conditions of the composites (prepared at $80^{\circ} \mathrm{C}$ and 50 or $70 \mathrm{rpm}$, respectively) do not seem to significantly affect the physical properties of the asphalt modified with those composites (M5 and M6). On the other hand, the addition sequence of the additives into the asphalt (as shown by the properties of the samples M3 and M4) has a greater effect on the physical properties of the asphalt blends, which indicates that the addition order determines the way in which CFP interacts with the heavy fractions of the asphalt through intermolecular forces, resulting in a high softening point and low phase separation and penetration values. However, the improvement of the physical properties of the modified asphalts is not as good as in the samples modified just with SBS or only with CFP (samples M1 and M2). As can be observed in Table 2, the best results correspond to those of the asphalt modified using just CFP (M2), a natural waste that was not subjected to any chemical process. This implies that the size reduction of the chicken feathers is sufficient for promoting the use of CFP as an efficient modifier of the physical properties of the asphalt.

Table 2. Effect of SBS/CF composite and CF on the physical properties of asphalt binder.

\begin{tabular}{ccccc}
\hline Code & $\begin{array}{c}\text { Softening Point, } \\
\mathbf{R} \& \mathbf{B}\left({ }^{\circ} \mathbf{C}\right)\end{array}$ & $\begin{array}{c}\text { Phase Separation } \\
\mathbf{R} \& \mathbf{(}\left({ }^{\circ} \mathbf{C}\right)\end{array}$ & $\begin{array}{c}\text { Penetration } \\
(\mathbf{d m m})\end{array}$ & $\begin{array}{c}\text { Rotational Viscosity, } \\
\mathbf{1 3 5}{ }^{\circ} \mathbf{C}(\mathbf{P a . s})\end{array}$ \\
\hline Asphalt & 52 & 0 & 44 & 0.545 \\
\hline M1 & 63 & 2.3 & 39.6 & 1.46 \\
\hline M2 & 64 & 0.5 & 28.0 & 1.533 \\
\hline M3 & 54.2 & 10 & 41.1 & 1.275 \\
\hline M4 & 60 & 7.5 & 36.5 & 1.430 \\
\hline M5 & 60 & 2.5 & 39.8 & 1.290 \\
\hline M6 & 60 & 4.5 & 41.6 & 1.202 \\
\hline
\end{tabular}


The softening temperature values after the phase separation test exhibited that the largest difference between the top and bottom parts of the collapsible tube, clearly corresponds to that of the asphalt binder modified with SBS and CFP in that addition order (M3). The incorporation of only CFP in the mixture causes a narrowing of the difference between the properties of the upper and lower regions of the tube; the difference fits into the range of the storage-stable mixtures as shown by the value of less than $1{ }^{\circ} \mathrm{C}$ for asphalt modified with only CFP (M2), the lowest value among all the tested materials, followed by $2.3^{\circ} \mathrm{C}$, shown by the asphalt modified with SBS (M1). The rest of the asphalts presented higher temperature gaps. This behavior indicates that the asphalt blend prepared with raw CFP was the most homogeneous. This behavior is attributed to the interaction between the amino acid groups of the keratin structure and the polar compounds of the asphalt, such as resins and asphaltenes. These interactions can be explained by the presence of three different mechanisms: (1) existence of rigid inclusions, (2) filler-asphalt interfacial effects and (3) reinforcement due to the filler volume produced by particle interaction $[8,22]$. Keratin has a complex structure that leads to an increased mechanical stability in the asphalt blend [23].

Similar behavior between polar particles has already been reported, e.g., nanoclays and asphalt heavy fractions [22] as well as oyster shell, which are mainly composed of calcium carbonate [8]. However, in the case of CFP, a better response in softening temperature and penetration was achieved.

The penetration test of all modified asphalts decreased with respect to the penetration of the unmodified asphalt (Table 2), since it varies from 6 to $36 \%$ of the original property. The penetration test is related to the consistency of the asphalt. Low penetration values indicate rigidity, which implies a reduction in its ductility and in the possibility of producing mechanical damage. The results of this study indicate that the best penetration value was obtained in the sample modified using only CFP (M2). The significant changes of the physical properties of this mixture are a consequence of the fact that the modification mechanism was not only limited to the friction among the chemical structures dispersed in the asphalt matrix, nor to the formation of rigid structural domains of styrene in the SBS structure [24]. Moreover, they also improved by means of the surface energy related to the modified CFP, which promotes their tendency to attract the chemical species that surround them, mainly by the chemical structure of keratin, which is the main component of CFP.

The viscosity of a dispersed system depends on the hydrodynamic interactions between the particles and the fluid, and particle-particle attractions that promote the presence of aggregates, floccules, or networks that increase the Brownian motion [22]. Table 2 shows rotational viscosity values of the asphalt blends at $135^{\circ} \mathrm{C}$. The sample with the highest viscosity was the asphalt modified with CFP (M2), slightly surpassing the SBS-modified asphalt (M1), followed by the asphalt modified with SBS/CFP prepared by adding CFP first (M4). The sample with the lowest viscosity was the one prepared with composite SBS/CFP at $50 \mathrm{rpm}$ (M5). These results point out that the viscosity is also affected by the presence of CFP; this behavior is very significant considering the origin of the modifier. The above mentioned increase in viscosity suggests the establishment of interactions between keratin and the asphalt polar fractions, such as asphaltenes and resins, as discussed earlier.

\subsection{Fluorescent Microscopy}

Figure 1a-f show the micrographs of the prepared asphalt blends. CFP-modified asphalt can be observed in Figure 1b, where the absence of fluorescence reveals a homogeneous dispersion attributed to a compatibility improvement of the asphalt polar components induced by the CFP nature. This phenomenon proves the previously discussed interaction effect. Oppositely, Figure 1e,f show the strongest fluorescence, suggesting that these samples are multiphased and, therefore, these blends are unstable. Apparently, this is caused by the partial swelling of the rubber in the presence of lighter crude-oil fractions [15]. Previous studies have reported that nanoparticles with certain functional groups can act as compatibility activators; in this case, the functional groups present in the keratin of CFP have a similar effect $[6,7]$. 

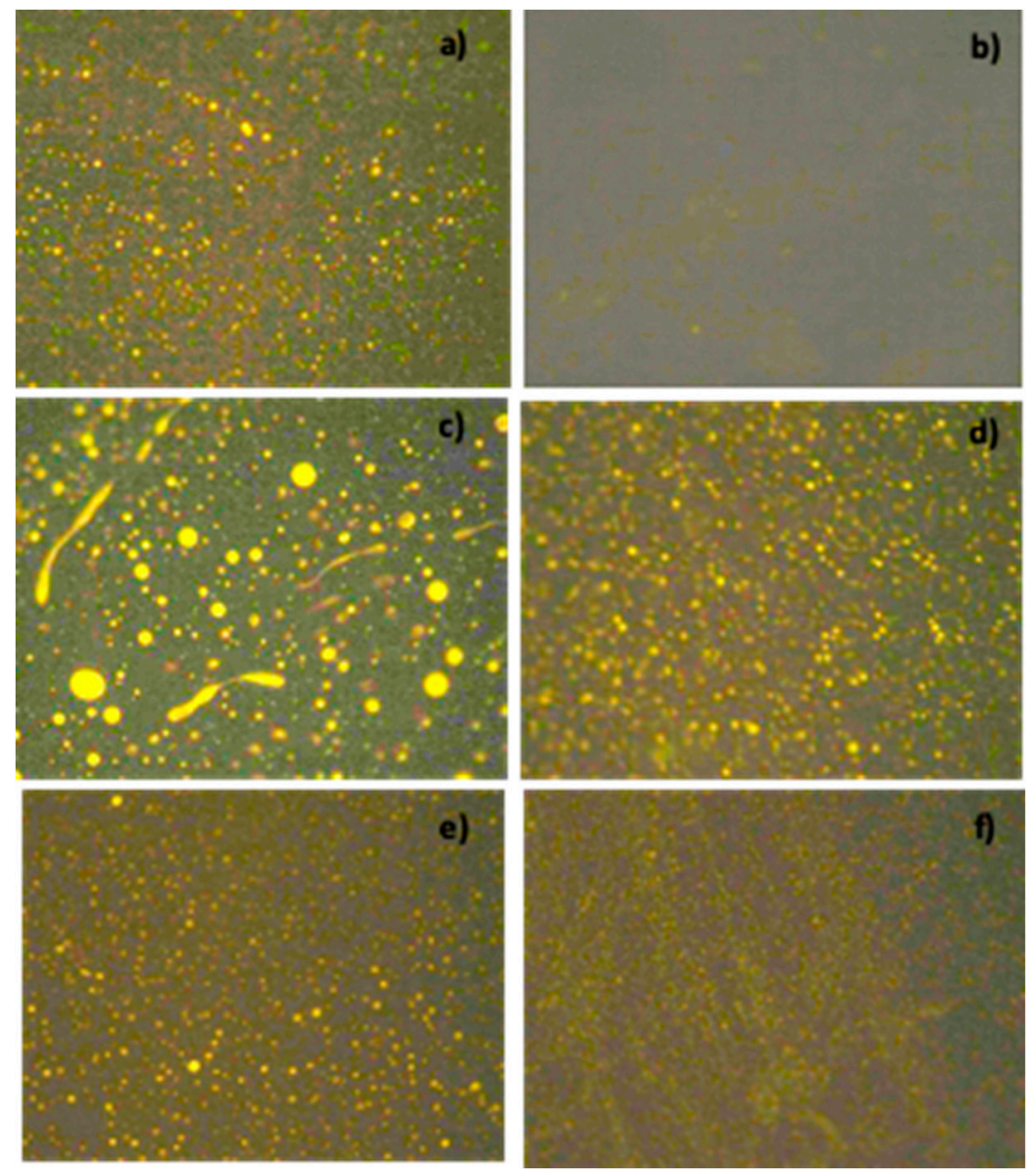

Figure 1. Fluorescene microscopy images: (a) M1, (b) M2, (c) M3, (d) M4, (e) M5, (f) M6.

Moreover, the SBS and CFP addition order was found to affect the dispersion pattern of the modifier in the blends, as lower dispersion degree was observed by adding SBS first. This also confirms what has been said about the keratin-asphalt interaction, which is higher compared to that of SBS-asphalt.

\subsection{Thermogravimetric Analysis (TGA)}

The thermal analysis has proven to be an important tool for evaluating the decomposition process of asphalt, through the analysis of curves of weight loss and derivative Thermogravimetry (DTG) [25].

Figure 2 shows TGA thermograms of the prepared asphalt blends. Raw CFP and SBS were tested independently for comparison. As observed, the CFP decomposition curve shows a weight loss stage at the range of $50-250^{\circ} \mathrm{C}$ attributed to the beginning of thermal decomposition of keratin [26], a second one at the range of $250-400{ }^{\circ} \mathrm{C}$ consistent with the keratin denaturation and disulfide bonds breakdown, and finally, a residue (about $18 \%$ ) at $1000^{\circ} \mathrm{C}$ [20]. The SBS thermogram showed a single decomposition stage ranging from 400 to $500{ }^{\circ} \mathrm{C}$, which is typical of this kind of material [20]. 


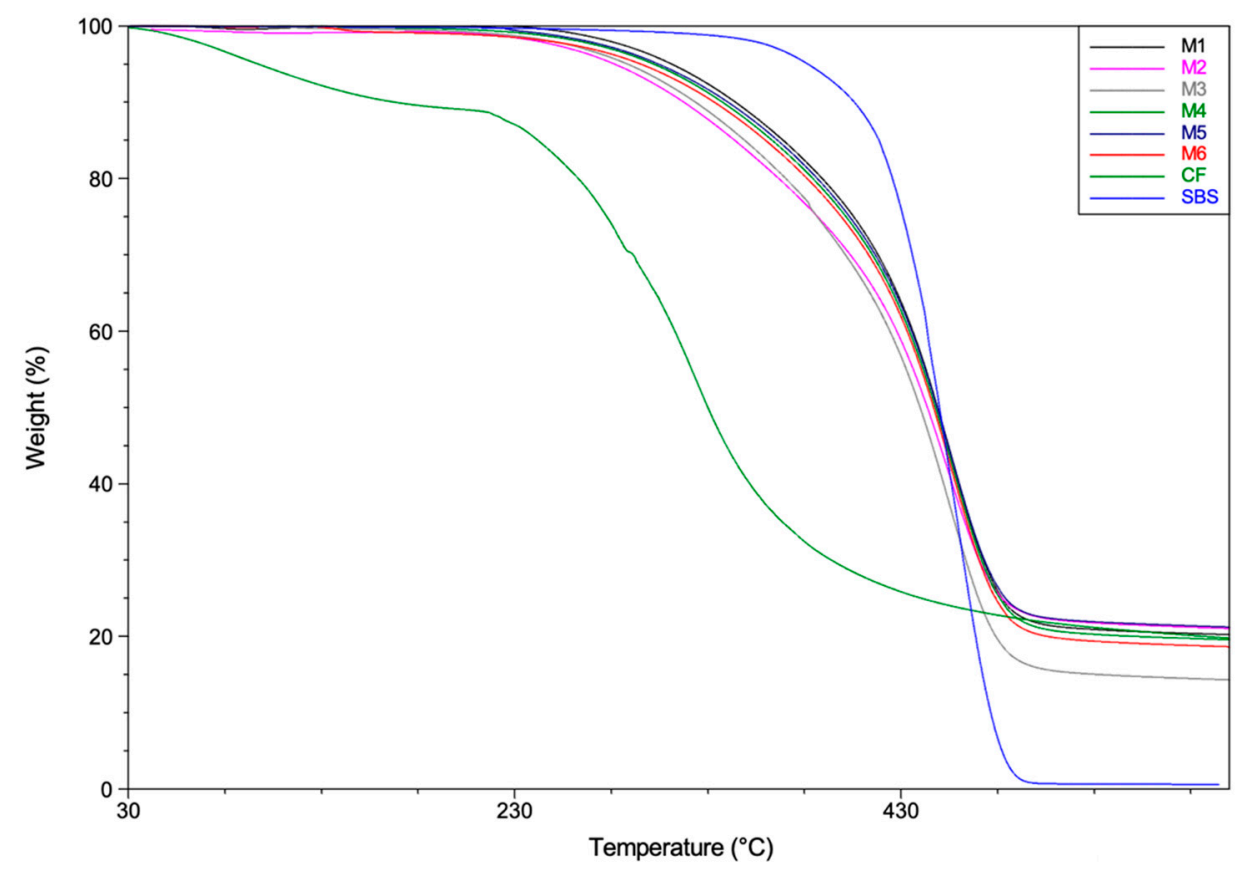

Figure 2. SDT (DSC/TGA) thermograms for SBS, CF, and modified asphalts M1-M6.

Asphalt blends prepared with CFP presented a weight loss stage from $250{ }^{\circ} \mathrm{C}$ to $500{ }^{\circ} \mathrm{C}$ with a residue of about $15 \%$, which is quite similar to that of raw CFP. In this region, the decomposition of asphaltenes has been reported before [27]. The multiple decomposition stages have also been reported for asphalt binders [28]. Given that the decomposition temperatures of the CFP and the asphalt are quite similar, the derivative weight loss curve (DTG) was obtained to determine the point corresponding to the most significant weight loss. A derivative weight loss curve can be used to indicate the point at which weight loss is most apparent and the temperature of the peak in the DTG corresponds to the temperature at which maximum degradation takes place. In addition, its quotient allows to determine the blend susceptibility to decomposition. In Figure 3, from the DTG curve it can be observed that the total decomposition of the asphalt blends takes place in a single stage around $480{ }^{\circ} \mathrm{C}$, far beyond the blending temperature and similar to the SBS decomposition temperature [29]. Even if the decomposition temperature of the modified asphalts is technically the same, their quotient shows slight variations, which indicates their susceptibility to degradation. The CFP-modified asphalt shows a lower quotient compared to the rest of the modified asphalts, which means that it is the least likely to suffer thermal weight loss; this may be due to the physical interactions between CFP and the heavy fractions of asphalt, which require more energy to break the bonding. Based on the results of this study, CFP by itself is the best modification agent for increasing the stability to decomposition at the same temperature, in contrast with either SBS or SBS/CFP composites. Additionally, these results confirm the compatibility between CFP and the asphalt [26]. This behavior can be attributed to the keratin structure, which makes the asphalt more resistant to temperature, even if its decomposition begins before SBS [29]. The addition order has a similar effect on the thermal stability, showing an improved behavior compared with that of the asphalt modified either only with SBS or with the SBS/CFP composites. 


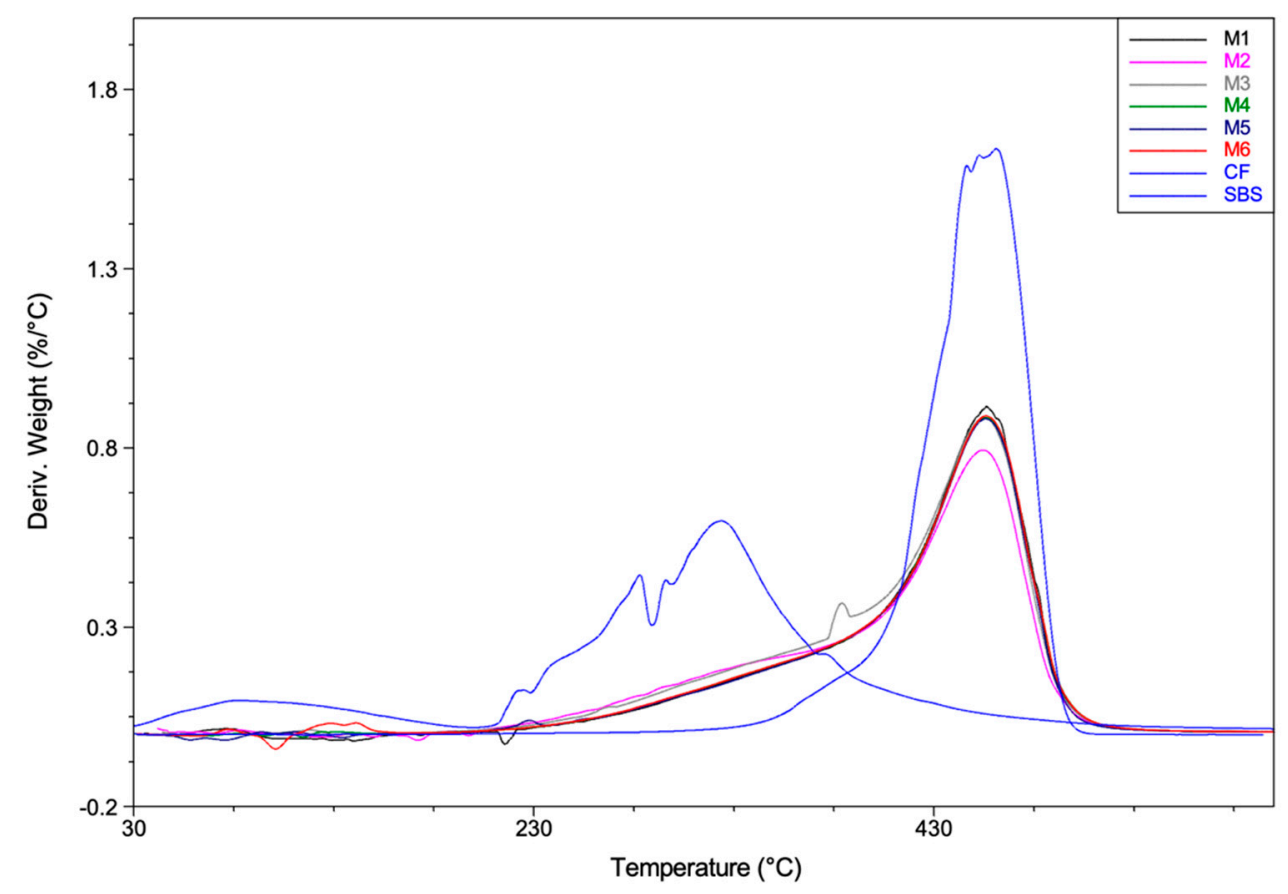

Figure 3. Derivative curve of weight loss signal obtained from TGA for SBS, CF and modified asphalts M1-M6.

\subsection{Rheology}

The $G^{*} / \sin \delta$ vs. temperature of the modified asphalts is shown in Figure 4 . In this context, complex modulus is related to the asphalt blend stiffness and $\mathrm{G}^{*} / \sin \delta$ represents the resistance of the modified asphalts to permanent deformations. The corresponding failure temperatures are indicated in the figure. The $\mathrm{G}^{*} / \sin \delta$ values of the modified asphalts are lower than that of the SBS-modified asphalt (control). The blend modified with $2 \%$ CFP (M2) is the closest to the reference value. The lowest values correspond to the samples incorporating the composites prepared at $80^{\circ} \mathrm{C}$ and 50 or $70 \mathrm{rpm}$ mixing speed. Therefore, the effect of using CFP as a modifier is more significant when it is added alone than when it is incorporated into the SBS/CFP composite, and its effect is similar to that of radial SBS. This means that CFP may equal the behavior of higher rubber loads; however, that study was not carried out in the present work. Keratin has a crosslinked structure similar to that of radial SBS, and then, it may be responsible for the similar rheological effects of both materials on the asphalt binder. The modifying effect becomes more evident above $85^{\circ} \mathrm{C}$, as previously reported $[30,31]$. Since $\mathrm{G}^{*} / \sin \delta$ indicates the degree of asphalt resistance to deformation when exposed to stress, it can be inferred that the CFP addition may be equivalent to the use of radial SBS in a wide range of thermal conditions. These results have not been reported before, given that CFP has not been studied previously.

The $\mathrm{G}^{*} / \sin \delta$ ratio is useful to determine the failure temperature of asphalts, i.e., the temperature at which the aforementioned parameter equals $1 \mathrm{kPa}$ (Figure 4), also known as $\mathrm{T}_{\text {SHRP. The resistance of }}$ modified asphalts to permanent deformations at high temperatures is rheologically described by $\mathrm{T}_{\mathrm{SHR}}$ as a softening point (from the physical perspective); at high temperatures, the higher the $\mathrm{T}_{\mathrm{SHRP}}$, the better the mechanical resistance properties of the asphalt. The results suggest that CFP interactions are efficient enough to affect both the thermal and mechanical properties of the asphalt, as a consequence of the dispersion of the CFP domains within the asphalt matrix [29]. However, the obtained values are not as high as others reported in reference works. 


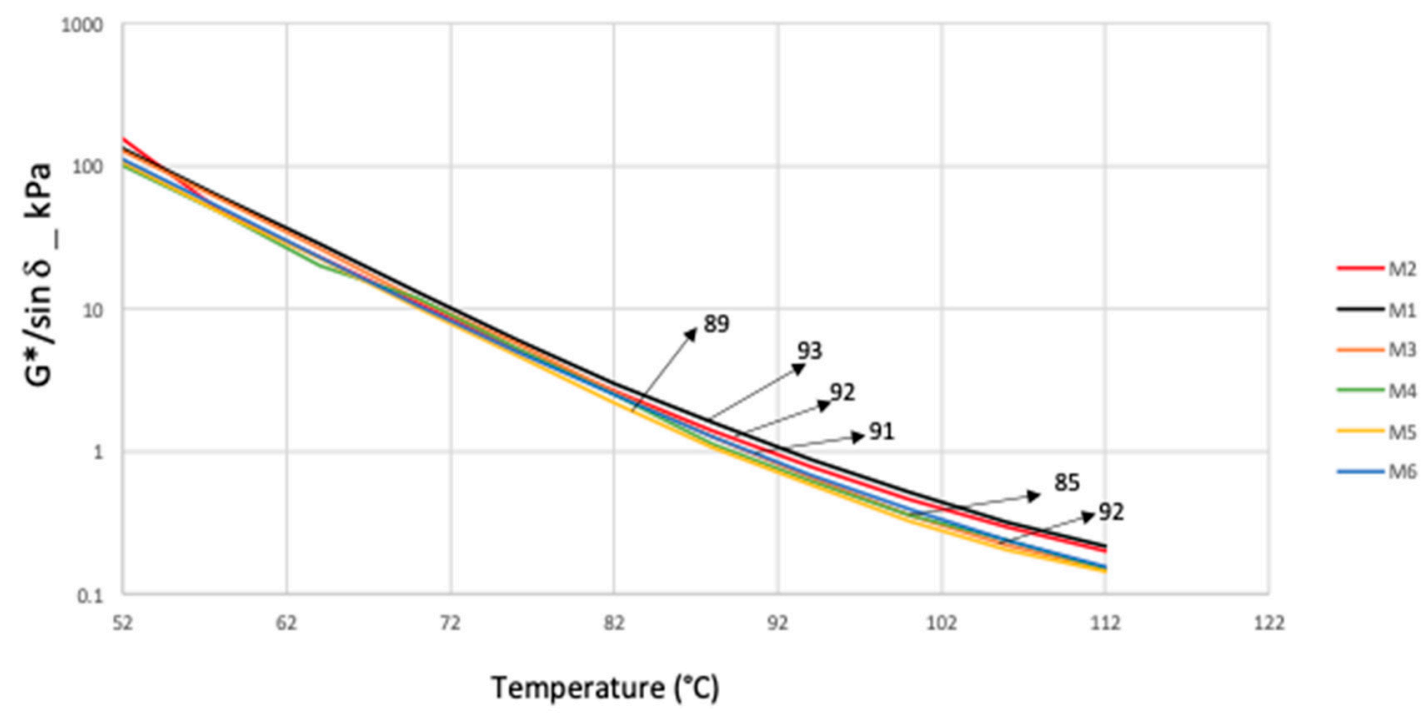

Figure 4. Isocronal plots of $\mathrm{G}^{*} / \sin \delta$ versus temperature of modified asphalt M1-M6.

The $\tan \delta$ measurements are generally preferred over $G^{*}$ due to their higher sensitivity to physical changes, as well as to the chemical structure of asphalts. Figure 5 shows the $\tan \delta$ isochronal curves at the same angular frequency considered for the construction of $G^{*}$ curves. The elastic response of the modified asphalts with CFP is better compared with that of the SBS-modified asphalt, since the elastic modulus is higher than the viscous modulus. The elastic nature of the asphalt is reduced as the temperature increases because the phase angle reaches an asymptotic value of 90 degrees, indicating that the asphalt shifts from a predominantly elastic behavior to a more significant viscous component. CFP-modified asphalt has the lowest tan $\delta$ value (even lower than that of the SBS-modified asphalt above $85^{\circ} \mathrm{C}$ ), suggesting that it will show a better elastic response before flowing.

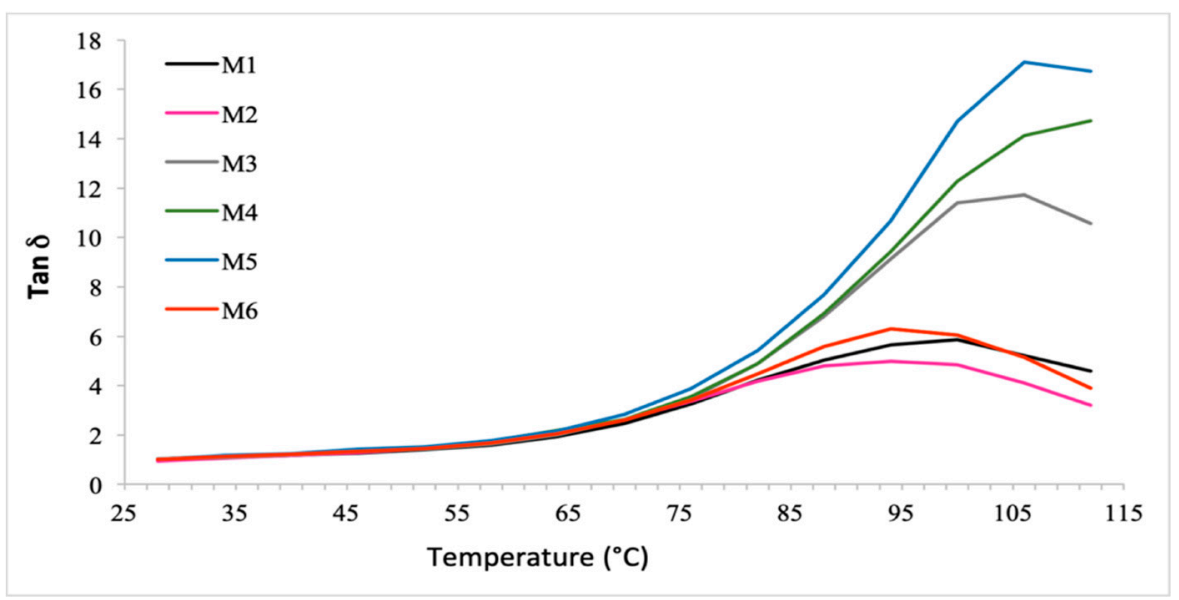

Figure 5. Isochronal plots of $\tan \delta$ versus temperature at $10 \mathrm{rad} / \mathrm{s}$ for modified asphalt M1-M6.

The SBS-modified asphalt (M1), the one modified with the composite prepared at $70 \mathrm{rpm}$ (M6) and the CFP-modified sample (M2) do not exhibit a sharp elastic-viscous behavior shift, unlike the rest of the materials, which show this evident transition with increasing tan $\delta$ above $80^{\circ} \mathrm{C}$. The latter behavior implies that M3, M4 and M5 would not withstand stress and thus, they are prone to develop failures like ruts, fractures and cracking. 


\section{Conclusions}

According to the results of this study, CFP showed that it can be considered as a potential material for asphalt modification, due to the improvements induced on the physical properties of the pure asphalt such as softening temperature, penetration, and phase separation, which resulted in increasing its stability and stiffness. The rheological properties of the asphalt modified with CFP, exhibited its reinforced elastic nature, which was very close to that of the asphalt modified directly with the pure SBS elastomer. These results suggest that CFP is a promising material that can be applied to partially replace the non-renewable asphalt binder modifiers that are extensively used in the construction of road infrastructure, without sacrificing the good performance of commercial asphalts. The addition sequence of SBS and CFP shows that when the last one is added first to the asphalt, the physical, thermal and rheological properties of the asphalt are enhanced, because it favors the interaction between CFP (particularly the keratin functional groups) and the heavy fractions of asphalt (like asphaltene and resins), resulting in particle-asphalt interfacial effects and a change in volume produced by particle interaction. The overall results of this study lead to the conclusion that the use of CFP for preparing modified asphalt mixtures is convenient not only because of the enhanced functional performance of the asphalt, but also because it is an efficient way of using a natural waste of great scientific potential that has not been extensively exploited yet.

Author Contributions: Conceptualization, L.M.C.-S., B.A.S.-C., M.Y.C.-C., A.B.M.-C. and J.L.R.-A.; methodology, L.M.C.-S., B.A.S.-C. and J.L.R.-A.; formal analysis, A.B.M.-C., B.A.S.C., L.M.C.-S., C.E.R.-G. and J.L.R.-A.; investigation, B.A.S.-C., A.B.M.-C., M.Y.C.-C. and J.L.R.-A.; resources, M.Y.C.-C., C.E.R.-G., B.A.S.-C. and A.B.M.-C.; data curation, C.E.R.-G., B.A.S.-C., A.B.M.-C. and J.L.R.-A.; writing-original draft preparation, A.B.M.-C., C.E.R.-G., B.A.S.-C., M.Y.C.-C. and J.L.R.-A.; writing-review and editing, B.A.S.-C., C.E.R.-G., and J.L.R.-A.; visualization, M.Y.C.-C., A.B.M.-C. and B.A.S.-C.; supervision, J.L.R.-A.; project administration, C.E.R.-G., A.B.M.-C. and B.A.S.-C.; funding acquisition, B.A.S.-C. and C.E.R.-G.

Funding: This research was funded by TECNOLÓGICO NACIONAL DE MÉXICO, grant number 6687.18-P.

Acknowledgments: The authors wish to thank to Eng. Luis Amezquita, Edgar Ramírez, Fabian Martínez and Abel Gaspar from TA instruments for facilities to carry out the rheological measurements. Also to Ergon Asfaltos and Dynasol Elastomeros S.A. de C.V., Altamira, México, for provide the materials for this research work.

Conflicts of Interest: The authors declare no conflict of interest.

\section{References}

1. Su, N.; Xiao, F.; Wang, J.; Cong, L.; Amirkhanian, S. Productions and applications of bio-asphalts-A review. Constr. Build. Mater. 2018, 183, 578-591. [CrossRef]

2. Zhang, R.; Wang, H.; Gao, J.; You, Z.; Tang, X. High temperature performance of SBS modified bio-asphalt. Constr. Build. Mater. 2017, 144, 99-105. [CrossRef]

3. Bao, D.X.; Yu, Y.Y.; Zhao, Q.M. Evaluation of the chemical composition and rheological properties of bio-asphalt from different biomass sources. Road Mater. Pavement Des. 2019, 1-16. [CrossRef]

4. Yang, X.; You, Z.; Dai, Q.; Mills-Beale, J. Mechanical performance of asphalt mixtures modified by bio-oils derived from waste wood resources. Constr. Build. Mater. 2014, 51, 424-431. [CrossRef]

5. Tang, S.; Williams, R.C. Antioxidant effect of bio-oil additive ESP on asphalt binder. In Proceedings of the 2009 Mid-Continent Transportation Research Symposium, Ames, IA, USA, 20-21 August 2009; p. 14.

6. Merusi, F.; Giuliani, F.; Polacco, G. Linear viscoelasticbehavior of asphalt binders modified with polymer/clay nanocomposites. Proc.-Soc. Behav. Sci. 2012, 53, 335-345. [CrossRef]

7. Mothè, M.G.; Leite, L.F.M.; Mothè, C.G. Thermal characterization of asphalt mixtures by TG/DTG, DTA and FTIR. J. Therm. Anal. Calorim. 2008, 93, 105-109. [CrossRef]

8. Nciri, N.; Shin, T.; Lee, H.; Cho, N. Potential of waste oyster shells as novel biofiller for hot-mix asphalt. Appl. Sci. 2018, 8, 415. [CrossRef]

9. Razzaq, A.K.; Yousif, R.A.; Tay, S.A. Characterization of hot mix asphalt modified by egg shell powder. Int. J. Eng. Res. Tech. 2018, 11, 481-492.

10. Sundstrom, D.W.; Kiel, H.E.; Daubenspeck, T.H. Use of byproduct lignins as extenders in asphalt. Ind. Eng. Chem. Prod. Res. Dev. 1983, 22, 496-500. [CrossRef] 
11. Arabani, M.; Tahami, S.A. Assessment of mechanical properties of rice husk ash modified asphalt mixture. Constr. Build. Mater. 2017, 149, 350-358. [CrossRef]

12. Caro, S.; Vega, N.; Husserl, J.; Alvarez, A.E. Studying the impact of biomodifiers produced from agroindustrial wastes on asphalt binders. Constr. Build. Mater. 2016, 126, 369-380. [CrossRef]

13. Abo-Sanab, Z.L.; Ragab, A.A.; Naguib, H.M. Improved dynamic mechanical properties of sustainable bio-modified asphalt using agriculture waste. Int. J. Pavement Eng. 2019, 1-7. [CrossRef]

14. Chen, C.; Podolsky, J.H.; Williams, R.C.; Cochran, E.W. Laboratory investigation of using acrylated epoxidized soybean oil (ESO) for asphalt modification. Constr. Build. Mater. 2018, 187, 267-279. [CrossRef]

15. Jahromi, S.G.; Khodaii, A. Effects of nanoclay on rheological properties of bitumen binder. Constr. Build. Mater. 2009, 23, 2894-2904. [CrossRef]

16. Zapién-Castillo, S.; Rivera-Armenta, J.L.; Chávez-Cinco, M.Y.; Salazar-Cruz, B.A.; Mendoza-Martínez, A.M. Physical and rheological properties of asphalt modified with SEBS/montmorillonite nanocomposite. Constr. Build. Mater. 2016, 106, 349-356. [CrossRef]

17. Fang, C.; Yu, R.; Liu, S.; Li, Y. Nanomaterials applied in asphalt modification: A review. J. Mater. Sci. Technol. 2013, 29, 589-594. [CrossRef]

18. Ahmed, K.; Nizami, S.S.; Raza, N.Z.; Kamaludin, S.; Mohmood, K. An assessment of rice husk ash modified, marble sludge loaded natural rubber hybrid composites. J. Mater. Environ. Sci. 2013, 4, 205-216.

19. Huang, Y.; Bird, R.N.; Heidrich, O. A review of the use of recycled solid waste materials in asphalt pavements. Resour. Conserv. Recycl. 2007, 52, 58-73. [CrossRef]

20. Méndez-Hernández, M.L.; Salazar-Cruz, B.A.; Rivera-Armenta,J.L.; Estrada-Moreno, I.A.; Chávez-Cinco, M.Y. Preparation and characterization of composites from copolymer styrene-butadiene and chicken feathers. Polimeros 2018, 28, 368-372. [CrossRef]

21. Castillo-Castillo, C.; Salazar-Cruz, B.A.; Rivera-Armenta, J.L.; Chávez-Cinco, M.Y.; Méndez-Hernández, M.L.; Estrada-Moreno, I.A.; Singh, S.; Singh, P.; Zitoune, R.; Yazdani, M. Futuristic Composites: Behavior, Characterization and Manufacturing; Springer: Berlin, Germany, 2018; pp. 297-318.

22. Schoff, C.K.; Kamarchik, P.J.; Herman, M.F. Encyclopedia of Polymer Science and Technology; John Wiley \& Sons Inc.: New York, NY, USA, 2014; pp. 1041-1049.

23. Senoz, E.; Wool, R.P.; McChalicher, C.W.J.; Hong, C.K. Physical and chemical changes in feather keratin during pyrolysis. Polym. Degrad. Stab. 2012, 97, 297-307. [CrossRef]

24. Golestani, B.; Moghaddas, F.; Sadeghpour, S. Performance evaluation of linear and non linear nanocomposite modified bitumens. Constr. Build. Mater. 2012, 35, 197-203. [CrossRef]

25. Conceicao, M.; Lucena, C.; Aguiar Soares, S. Characterization ad thermal behavior of polymer-modified asphalt. Mater. Res. 2004, 7, 529-534.

26. Prochon, M.; Janowska, G.; Przepiorkowska, A. Thermal properties and combustibility of elastomer-protein composites, Part I. Composites SBR-keratin. J. Therm. Anal. Calorim. 2012, 109, 1563-1570. [CrossRef]

27. Bonati, F.; Merusi, G.; Polacco, S.; Filippi Giuliani, F. Ignitability and thermal stability of sphalt binders and mastics for flexible pavements in highway tunnels. Constr. Build. Mater. 2012, 37, 660-668. [CrossRef]

28. Naskar, M.; Chaki, T.K.; Reddy, K.S. Effect of waste plastic as modifier on thermal stability and degradation kinetics of bitumen/waste plastics blends. Thermochim. Acta 2010, 509, 128-134. [CrossRef]

29. Munteanu, S.B.; Brebu, M.; Vasile, C. Thermal and thermo-oxidative behavior of butadiene-styrene copolymers with ifferent architectures. Polym. Degrad. Stab. 2005, 89, 501-512. [CrossRef]

30. Ouyang, C.; Wang, S.; Zhang, Y.; Zhang, Y. Preparation and properties of styrene-butadiene-styrene copolymer/kaolinite clay compound and asphalt modified with the compound. Polym. Degrad. Stab. 2005, 87, 309-317. [CrossRef]

31. Martínez-Anzures, J.D.; Zapién-Castillo, S.; Salazar-Cruz, B.A.; Rivera-Armenta, J.L.; Antonio-Cruz, R.C.; Hernández-Zamora, G. Preparation and properties of modified asphalt using branch SBS/nanoclay nanocomposites as a modifier. Road Mater. Pavement Des. 2019, 20, 1275-1290. [CrossRef]

(C) 2019 by the authors. Licensee MDPI, Basel, Switzerland. This article is an open access article distributed under the terms and conditions of the Creative Commons Attribution (CC BY) license (http://creativecommons.org/licenses/by/4.0/). 